on account of the grant for the year 1937-38 and 1938-39 and, subject to the vote of the Legislative Assembly, steps will be taken to pay this amount early in the year 1938-39.

\section{Devices for Fighting Fires}

Is the High Tension Conference held in Paris in June interesting discussions took place as to the relative merits of fire-fighting equipment. In Part 2 of an article by T. Rich in the Electrician of July 16, the latest opinions of French engineers on the devices used in practice are given. For protecting transformers and alternators of large output, alarm indicators are used as well as extinguishing appliances. They are of the fixed type which operate automatically when the station has no attendants and when the generators are very large. The movable apparatus generally used consists of extinguishers, boxes of sand, blankets and water jets directly connected to the mains or to a foam generator. Gas masks, smoke fans and emergency lamps are auxiliary apparatus. Portable extinguishers are only used for very small fires. It is important that the material used should be a bad conductor of electricity, as small fires make a close approach necessary and the jet may give a dangerous shock. Carbon tetrachloride has high extinguishing powers and it is not a good conductor. But at high temperatures it decomposes into a gas that is corrosive and poisonous, so that a gas mask is desirable although it entails a loss of time. Methyl bromide is generally thought to give out less poisonous fumes but it is expensive. Saline solutions with a base of potash have a high extinguishing capacity but they are dangerous to use as the jet is a conductor. Carbonic acid snow is not such a good extinguisher but its use entails no danger to personnel. It can be used without cutting off the current, and so is useful in the case of small fires, but the risk of re-ignition is serious. Fire-resisting blankets are used to put out burning clothes on persons. They should be kept in metallic cases with anti-moth material and a window should be put in the case to ensure that the contents have not been borrowed for other purposes. - 'Atomized' jets which work under a high pressure have been found useful both in putting out oil fires and cable fires. For hoses rubber is better than woven material. Each 'fire' point at an electric station should have a sand box with wood shovels, a gas mask and a lantern.

\section{Annual Report of the Ministry of Health}

THE eighteenth annual report of the Ministry of Health, 1936-37, has been recently issued (H.M. Stationery Office. 5s. net). It consists of an introduction and seven chapters, and includes the work of the Welsh Board of Health. The death-rate was $9 \cdot 2$ per thousand, the death-rate of infants below one year 59 , and the maternal mortality rate $3 \cdot 81$, per 1,000 live births. Tuberculosis mortality was the lowest on record, being a rate per million living of 583 for pulmonary, and of 109 for non-pulmonary, tuberculosis. Notifications of diphtheria were 7,290 less than for 1935, but still considerably in excess of those for 1933. Of enteric fever, 2,493 cases were notified, compared with 1,750 in 1935 , the increase being mainly due to the epidemic last summer at Bournemouth, Poole and Christchurch. Public analysts examined 146,438 samples of food and drugs -a record number - of which 7,802 were reported against. Of this total, 80,082 were samples of milk and 7,588 those of butter. Under slum clearance and rehousing, up to the end of last year 100,355 houses had been demolished and 127,553 houses built to replace them, this being the fourth year of the five years' plan. This year, general progress in town and country planning, especially in preserving the countryside, has markedly increased. No less a sum than $£ 65,000,000$ of Exchequer money was spent in 1936 on services administered by the Ministry, but only $£ 2,200,000$ of this was expended on central administration.

\section{Apparatus for Testing Petroleum and Related Products}

A catalogue of scientific apparatus is necessarily a classified list of separate items and to repay reading must be clearly printed, attractively set out, adequately illustrated and up to date. Messrs. Gallenkamp and Co.'s catalogue (No. 96A, 1937 Edition) listing apparatus for testing petroleum, tar, asphalt and their products, fulfils all these requirements and will be of definite interest to those engaged in the examination of these substances. The listed apparatus includes types standardized for routine tests by the Institution of Petroleum Technologists, the Standardization of Tar Products Test Committee, the British Standards Institution and the American Society for Testing Materials, as well as many other special forms which for one reason or another have not been so standardized. The drawings, in general, have been executed with due attention to detail, although on p. 35, an unsuitable type of ring burner has been included in the diagram of the apparatus for the determination of water in asphaltic substances ; on p. 43, the position of the thermometer in the $\mathrm{R}$ and $\mathrm{B}$ softening point apparatus is incorrect and on the same page, the $K$ and $S$ softening point apparatus depicted is not the standard type specified by the S.T.P.T.C. The arrangement of the subdivisions is at present somewhat haphazard, neces. sitating frequent reference to the index; it could be improved by the substitution of an alphabetic order on the lines of the Institution of Petroleum Technologists' hand-book. Despite these defects, the catalogue will be appreciated by technologists specializing in the fields indicated in the title.

\section{Natural Colour Eclipse Photography}

WE have received from Mr. Edward R. Hewitt, of 127 East 2lst Street, New York, a correction of the statement, quoted in Nature of March 13, that the National Geographic Magazine of February contained the first natural colour photograph of a total solar eclipse ever reproduced. Mr. Hewitt informs us that the Scientific American of April 1925 reproduced a colour photograph, made by him, of the total eclipse of January 24, 1925, and has sent 